\title{
Post subthalamic area deep brain stimulation for tremors: a mini-review
}

\author{
Tao Xie $^{1 *}$, Jacqueline Bernard ${ }^{1}$ and Peter Warnke ${ }^{2}$
}

\begin{abstract}
Deep brain stimulation (DBS) in the thalamic ventrointermediate nucleus (VIM) is the traditional target for the surgical treatment of pharmacologically refractory essential tremor or parkinsonian tremor. Studies in recent years on DBS in posterior subthalamic area (PSA), including the zona incerta and the prelemniscal radiation, have shown promising results in tremor suppression, particularly for those tremors difficult to be well controlled by VIM DBS, such as the proximal postural tremor, distal intention tremor and some cerebellar outflow tremor in various diseases including essential tremor and multiple sclerosis. The adverse effect profile of the PSA DBS is mild and transient, without lasting or striking dysarthria, disequilibrium or tolerance, in contrast to VIM DBS, particularly bilateral DBS. However, the studies on PSA DBS so far are still limited, with a handful of studies on bilateral PSA, and a short follow up duration compared to VIM. More studies are needed for direct comparison of these targets in the future. A review here would help to gain more insight into the benefits and limits of the PSA DBS compared to that in VIM in the clinical management of various tremors, particularly for those difficult to be well controlled by traditional VIM DBS.
\end{abstract}

Keywords: Post subthalamic area, Zona incerta, Deep brain stimulation, Tremor

\section{Introduction}

Deep brain stimulation (DBS) in thalamic ventrointermediate (VIM) nucleus is the traditional target for the surgical treatment of pharmacologically refractory essential tremor (ET) or parkinsonian tremor. Studies in recent years on DBS in the posterior subthalamic area (PSA), including the zona incerta $(\mathrm{Zi})$ and the prelemniscal radiation (Raprl), have shown promising results in tremor suppression [1-25], particularly for those difficult to be controlled by VIM DBS, such as the proximal postural tremor, distal intention tremor and some cerebellar outflow tremor in ET, multiple sclerosis (MS), posttraumatic tremor (PTT), cerebellar tremor (CT), Holmes tremor (HT) and spinocerebellar ataxia 2 (SCA2) $[8,12-14,16]$. The adverse effect profile of the PSA DBS is mild and transient, without lasting or striking dysarthria, disequilibrium or tolerance, as would have been seen in the VIM DBS, particularly bilateral DBS [26-30]. However, the studies on PSA are still limited given less

\footnotetext{
* Correspondence: txie@bsd.uchicago.edu

'Department of Neurology, University of Chicago Medical Center, Chicago, IL 60637, USA

Full list of author information is available at the end of the article
}

than 30 publications in the PubMed so far, with even a handful of studies performed on bilateral PSA, and a short follow up duration compared to VIM. Therefore, a mini-review on DBS in PSA is needed to gain more comprehensive insight into the potential benefits and limits of the PSA DBS compared to that in VIM DBS in the clinical management of various tremors, particularly for those tremors difficult to be well controlled by traditional VIM DBS.

\section{DBS in PSA: evidence on effective tremor control and others}

Anatomically, the PSA is bounded anteriorly by the posterior border of the subthalamic nucleus (STN), superiorly by the ventral thalamic nuclei, inferiorly by the dorsal border of the substantia nigra, posteriorly by the medial lemniscus, posteromedially by the anterolateral border of the red nucleus, posterolaterally by the ventrocaudal nucleus, and laterally by the posterior limb of the internal capsule [31]. It consists of $\mathrm{Zi}$ and the Raprl. The $\mathrm{Zi}$ lies dorsal and posterior to STN, joining both the basal gangalia thalamocortical circuit and the cerebellar thalamocortical circuit. The $\mathrm{Zi}$ anatomically also consists 
Table 1 PSA DBS publications: indications, targets, results and side effects

\begin{tabular}{|c|c|c|c|c|}
\hline Series (reference number) & $\begin{array}{l}\text { Patients/procedures/time } \\
\text { to assess }\end{array}$ & $\begin{array}{l}\text { Target and/or stereotactic } \\
\text { parameters }\end{array}$ & Results & Side effects \\
\hline Mundinger, 1977 [1] & $\begin{array}{l}7 \text { torticollis, unilateral, } \\
\text { stimulation } 30-40 \text { minutes. }\end{array}$ & $\begin{array}{l}\text { cZi; in some cases combined } \\
\text { with other structures }\end{array}$ & $\begin{array}{l}\text { Good control of the } \\
\text { torticollis }\end{array}$ & No \\
\hline $\begin{array}{l}\text { Brice and McLellan, } \\
1980 \text { [2] }\end{array}$ & $\begin{array}{l}2 \mathrm{MS} \text {, bilateral, } \\
\text { post-op } 6 \text { months }\end{array}$ & $\begin{array}{l}10 \mathrm{~mm} \text { lateral/20mm behind } \\
\mathrm{AC} / 6-8 \mathrm{~mm} \text { below ICL (AC: } \\
\text { anterior commissure; } \\
\text { ICL: inter-commissural line) }\end{array}$ & $\begin{array}{l}\text { "Striking improvement" } \\
\text { in intention tremor }\end{array}$ & $\begin{array}{l}\text { Transient worsening of swallowing, } \\
\text { speech, and micturition, all resolved in } \\
3 \text { weeks but dysarthria. }\end{array}$ \\
\hline Andy, 1983 [3] & 1 PTT, unilateral & $\begin{array}{l}7 \mathrm{~mm} \text { lateral/ } 8.5 \mathrm{~mm} \text { behind } \\
\mathrm{MCP} / 1 \mathrm{~mm} \text { below ICL (MCP: } \\
\text { middle-commissural point) }\end{array}$ & $\begin{array}{l}\text { Complete cessation } \\
\text { of tremor }\end{array}$ & Unknown \\
\hline Kitagawa et al., 2000 [4] & $\begin{array}{l}1 \mathrm{ET} \text { and } 1 \text { DT, unilateral, } \\
\text { intra-op stimulation and } \\
\text { post-op } 1 \text { week }\end{array}$ & $\begin{array}{l}\mathrm{Zi}, 3 \mathrm{~mm} \text { under the border } \\
\text { of the VIM }\end{array}$ & $\begin{array}{l}\text { Abolition of ET; "remarkable" } \\
\text { decrease in DT and dystonia }\end{array}$ & $\begin{array}{l}\text { Transient paresthesia, palm hyperhidrosis, } \\
\text { anorexia, and disequilibrium }\end{array}$ \\
\hline Hooper et al., 2001 [5] & $\begin{array}{l}1 \mathrm{PTT} \text {, unilateral, } \\
\text { post-op } 44 \text { months }\end{array}$ & $\begin{array}{l}12 \mathrm{~mm} \text { lateral/ } 6 \mathrm{~mm} \text { behind } \\
\mathrm{MCP} / 4 \mathrm{~mm} \text { below ICL }\end{array}$ & $\begin{array}{l}\text { Sustained microtomy effect. } \\
\text { No IPG needed. }\end{array}$ & Shoulder weakness, resolved in 3 days. \\
\hline Velasco et al., 2001 [6] & $\begin{array}{l}10 \mathrm{PD} \text {, unilateral, } \\
\text { post-op } 12 \text { months }\end{array}$ & $\begin{array}{l}\text { Expressed in tenths of the } I C L \text { : } \\
\text { laterality } 5 / 10,8 / 10 \text { behind } A C \text {, } \\
1-2 / 10 \text { below } I C L \text {, targeting } \\
\text { Raprl }\end{array}$ & $\begin{array}{l}\text { Significant improvement in } \\
\text { tremor and rigidity; } \\
\text { Mild improvement in } \\
\text { bradykinesia. }\end{array}$ & $\begin{array}{l}1 \text { worsening pre-existing depression, } \\
1 \text { transient diplopia, } 3 \text { transient dysarthria }\end{array}$ \\
\hline Murata et al., 2003 [7] & $\begin{array}{l}8 \mathrm{ET} \text {, unilateral, } \\
\text { post-op } 22 \text { months (8-42) }\end{array}$ & $\begin{array}{l}\text { Best } 11 \mathrm{~mm} \text { lateral } / 7.5 \mathrm{~mm} \text { behind } \\
\mathrm{MCP} / 4 \mathrm{~mm} \text { below } \mathrm{ICL} \text { in } \mathrm{Zi} \\
\text { and Raprl }\end{array}$ & $\begin{array}{l}\text { Contralateral tremor } \\
\text { decreased by } 81 \%\end{array}$ & $\begin{array}{l}\text { Only stimulation induced that did not } \\
\text { affect result. }\end{array}$ \\
\hline Nandi and Aziz, 2004 [8] & $\begin{array}{l}15 \mathrm{MS}, 6 \text { bilateral, } 9 \text { unilateral, } \\
\text { post-op } 15 \text { months in } 10 \text { patients }\end{array}$ & $\mathrm{Zi}$ & $\begin{array}{l}\text { Contralateral postural tremor } \\
\text { decreased by } 64 \% \text {, } \\
\text { intention tremor by } 36 \%\end{array}$ & $\begin{array}{l}\text { Transient paresthesia, mild dysarthria and } \\
\text { seizure in } 1 \text { and infection in } 2 \text { patients. }\end{array}$ \\
\hline Plaha et al., 2004 [9] & 4 ET, bilateral, post-op 12 months & $\begin{array}{l}\text { Medial to the posterior dorsal } \\
\text { third of the STN }\end{array}$ & $\begin{array}{l}\text { Total tremor decreased by } \\
80 \% .2 \text { patients with severe } \\
\text { head tremor completely } \\
\text { resolved. No tolerance. } \\
\text { Low volt } 1.8 \text {. }\end{array}$ & No dysarthria or dysequilibrium. \\
\hline Kitagawa et al., 2005 [10] & 8 PD, unilateral, post-op 24 months & $\begin{array}{l}\text { Best contact } 10.5 \mathrm{~mm} \\
\text { lateral/5.6mm } \\
\text { behind } \mathrm{MCP} / 3.2 \mathrm{~mm} \\
\text { below } \mathrm{ICL}\end{array}$ & $\begin{array}{l}\text { UPDRS-III improved by } 44.3 \% \text {, } \\
\text { tremor by } 78.3 \% \text {, rigidity by } \\
92.7 \% \text { and akinesia by } 65.7 \% \text {. }\end{array}$ & Mild adverse events \\
\hline Plaha et al., 2006 [11] & $\begin{array}{l}35 \text { PD, } 29 \text { bilateral, } 6 \text { unilateral, } \\
\text { post-op } 6 \text { months }\end{array}$ & $\begin{array}{l}\text { cZi: posteromedial to the } \\
\text { post-dorsal STN }\end{array}$ & $\begin{array}{l}\text { cZi better than STN in reducing } \\
\text { UPDRSIII by } 76 \% \text {, tremor by } 93 \% \text {, } \\
\text { rigidity by } 76 \% \text { and bradykinesia } \\
\text { by } 65 \% \text { in cZi vs by } 55 \%, 61 \% \text {, } \\
50 \% \text { and } 59 \% \text { in STN. }\end{array}$ & $\begin{array}{l}\text { No complication in Zi No difference } \\
\text { in dyskinesia, L-dopa reduction, and } \\
\text { stimulation parameters. }\end{array}$ \\
\hline Freund et al., 2007 [12] & 1 SCA2, bilateral, post-op 2 years & $\begin{array}{l}\text { Combined VOP-VIM/Zi-Cerebellar } \\
\text { thalamic projection (VOP: ventro- } \\
\text { oralis posterior). }\end{array}$ & $\begin{array}{l}\text { Nearly complete cessation of } \\
\text { tremor and torticollis } \\
\text { by stimulation to distal contacts }\end{array}$ & No complication mentioned \\
\hline Hamel et al., 2007 [13] & $\begin{array}{l}8 \mathrm{ET}, 2 \mathrm{MS}, 1 \mathrm{SCA} \text {, bilateral, post-op } \\
\text { at least } 3 \text { months, most of them > 1year }\end{array}$ & $\begin{array}{l}12.7 \mathrm{~mm} \text { lateral } / 7 \mathrm{~mm} \text { behind } \\
\mathrm{MCP} / 1.5 \mathrm{~mm} \text { below ICL }\end{array}$ & $\begin{array}{l}\text { Reducing intention tremor by } \\
68 \% \text { to } 73 \% \text {. PSA better }\end{array}$ & $\begin{array}{l}\text { Paresthesia, dysarthria, gait ataxia, } \\
\text { unknown number }\end{array}$ \\
\hline
\end{tabular}


Table 1 PSA DBS publications: indications, targets, results and side effects (Continued)

Herzog et al., 2007 [14]

10ET, bilateral, and 11MS, 6 bilateral,

5 unilateral, post-op at least 4 months

Carrillo-Ruiz et al., 2008 [15] 5 PD, bilateral, post-op 12 months

Plaha et al., $2008[16]$

$6 \mathrm{ET}, 5 \mathrm{PD}, 4 \mathrm{MS}, 1 \mathrm{CT}, 1 \mathrm{HT}$

1 DT/bilateral, post-op 12 months

Blomstedt et al., 2009 [17]

Blomstedt et al., 2010 [18]

Fytagoridis and

Blomstedt, 2010 [19]

Barbe et al., 2011 [20]

Blomstedt et al., 2011 [21]

Blomstedt et al., 2011 [22]

Blomstedt et al., 2011 [23]

Blomstedt et al., 2012 [24]
2DT, WC (writer's cramp),1CT, all unilateral, post-op 1 year

21ET, 2 bilateral, 19 unilateral post-op 1 year.

27 ET, 8 PD, 2 DT, 1 CT, 1 WC, all unilateral except 4 bilateral unknown disease, post-op 34 months

21ET, bilateral 19,2 unilateral post-op at least 3 months

4 ET unilateral, one in STN one in cZi, post-op 1-6 years

5ET, failed VIM, no info on post-op duration except in "years"

68 ET, 34VIM and 34 PSA, only 3 each bilateral, post-op 28 months for VIM and 12 month for PSA

14 PD, 13 unilateral, 1 bilatera post-op 18 months
In PSA region, no details

Active contacts: $11.5 \mathrm{~mm} / 6.5 \mathrm{~mm}$ behind MCP and $4.5 \mathrm{~mm}$ below ICL

Posteromedial to the

posterodorsal STN

Active $10.3 \mathrm{~mm} / 6.1 \mathrm{~mm}$ behind $\mathrm{MCP} / 3.5$ below $I C L$, in PSA

PSA active contact $11.6 \mathrm{~mm}$ lateral/6.3mm behind $\mathrm{MCP} / 3 \mathrm{~mm}$ below ICL.

Active $12.0 \mathrm{~mm} / 6.1 \mathrm{~mm}$ behind $M C P / 1.5 \mathrm{~mm}$ below ICL, all in PSA

26 sub- ICL and 14 above ICL electrodes. The mean sub-ICL $11.3 \mathrm{~mm}$ lateral $/ 7.2 \mathrm{~mm}$ behind MCP/1.4mm below

$\mathrm{ICL}$, the thalamic $12.6 \mathrm{~mm}$

lateral/5.7mm behind MCP/1.0mm above ICL.

CZi $9.5-15.5 \mathrm{~mm}$ lateral/1.3-9.4mm behind MCP/0.2 $\mathrm{mm}$ above to $6.8 \mathrm{~mm}$ below $\mathrm{ICL}$

cZi, $11.4 \mathrm{~mm}$ lateral $/ 6.8 \mathrm{~mm}$ behind $\mathrm{MCP} / 2.9 \mathrm{~mm}$ below $\mathrm{ICL}$

Vim 13-15mm lateral/6-7mm before PC/Omm on ICL. PSA: posteromedia to the tail of the STN at the level of maxim diameter red nucleus

(PC: posterior commissure)

Posterior and medial to the posterior tail of the STN at than VIM unless limited by

side effects

PSA better than VIM in postural

Unknown

reduction, by 64\% in ET and by

$50 \%$ in MS.

UPDRS III decreased by $65 \%$,

tremor by $90 \%$, rigidity

by $94 \%$, bradykinesia by $75 \%$

PD tremor improved by $92 \%$

rigidity by $77 \%$,

bradykinesia by $62 \%$. Tremor

improved in ET by $76 \%$.

MS, 57\%; CT, 60\%; HT, 70\%;

DT, $71 \%$. Low volts

87\% tremor reduction

Reducing tremor of upper

extremity by $95 \%$,

hand function by $87 \%$

improving ADL by $66 \%$

24 non-PD tremor

decreased by $91 \%$

Sub-|CL stimulation is more

efficient than thalamic

stimulation but equally

effective when patients

individual stimulation

parameters are used.

CZi more efficient than STN

Comparable, dysarthria, dystonia dizziness, blurred vision.

CZi achieved improvement

in tremor control after

VIM failed, 57\% cZi v

$25 \%$ VIM

Tremor in the treated hand

mproved by $70 \%$ in VIM

and $89 \%$ in PSA.

1 deterioration of pre-existing depression,

5 transient somnolence, 1 transient dysarthria

2 transient dysequilibrium

1 transient dysphagia

Unknown

8 transient expressive dysphasia, 1 transient clumsy hand and leg.

1 transient hemiparesis, 1 infection, 22\% transient dysphasia.

Paresthesia in $3 / 26$, and dysarthria in $2 / 26$ electrodes

Unknown

Unknown

stimulation induced side effect, 1 infection 
Table 1 PSA DBS publications: indications, targets, results and side effects (Continued)

\begin{tabular}{|c|c|c|c|c|}
\hline & & $\begin{array}{l}\text { the maximal diameter of } \\
\text { the RN. Active contact } 12.6 \mathrm{~mm} \\
\text { lateral/7mm post } \mathrm{MCP} / 2 \mathrm{~mm} \\
\text { below ICL }\end{array}$ & $\begin{array}{l}\text { Tremor reduction by } 82.2 \% \text {, } \\
\text { rigidity by } 34.3 \% \text {, } \\
\text { bradykinesia by } 26.7 \%\end{array}$ & \\
\hline Fytagoridis et al., 2012 [25] & $\begin{array}{l}18 \mathrm{ET}, 16 \text { unilateral and } 2 \text { bilateral, } \\
\text { post-op } 4 \text { years on average }\end{array}$ & $\begin{array}{l}\mathrm{CZi}, 12.0 \mathrm{~mm} \text { lateral } / 6.3 \mathrm{~mm} \\
\text { behind } \mathrm{MCP} / 2.2 \mathrm{~mm} \\
\text { below } \mathrm{ICL} \text {, in posterior-medial } \\
\text { to STN at the level of the } \\
\text { maximal diameter of red } \\
\text { nucleus }\end{array}$ & $\begin{array}{l}\text { Improved total tremor by } 51.4 \% \text {, } \\
\text { upper extremity } \\
\text { by } 89.4 \% \text {, hand function by } 78.5 \% \text {. } \\
\text { No increase in stimulation over } \\
\text { the course }\end{array}$ & Mild and transient, 1 hard ware related. \\
\hline
\end{tabular}


of caudal part and rostral part. The Raprl is a fiber bundle that lies posterior to the STN, separated from it by the intervening $\mathrm{Zi}$. It contains fibers from the mesencephalic reticular formation that projects to the thalamus as well as ascending cerebellothalamic fibers. The Forel H1 (thalamic fasciculus) and H2 (lenticular fasciculus) lies dorsal to the STN and immediately anterior to the PSA, and the Forel $\mathrm{H}$ lies anterior to the red nucleus.

Whilst the $\mathrm{Zi}$ was a target for lesioning since the early sixties, DBS in PSA was first reported by Mundinger in 1977 [1]. The intraoperative stimulation of the $\mathrm{Zi}$ and surrounding area obtained good control of torticollis in 7 patients without complications [1]. Successful results were also reported by Brice and McLellan in 1980 and Andy in 1983 [2,3]. The unsophisticated DBS devices, the successful therapeutic effects of levodopa in Parkinson's disease (PD), and the successful DBS on VIM by Benabid in 1987 [32] are all possible reasons for the lack of sufficient reports during that period of time. In 2000, a successful attempt on the DBS targeting $\mathrm{Zi}$ in controlling intention tremor in ET and dystonic tremor (DT), which were hard to be controlled otherwise by DBS targeting VIM, was reported by Kitagawa et al. [4]. This study reignited the interest of DBS targeting $\mathrm{Zi}$ and more broadly PSA. Since then, more than 20 articles have been published, as listed in the Table 1, including 201 cases of ET, 99 cases of PD, 32 cases of MS, 6 cases of DT, and several others (PTT, CT, HT, WC, and SCA) [1-25]. The majority of the DBS was placed unilaterally. Only about $25 \%$ of the cases had bilateral DBS (Table 1). They were followed up for 3 months to 6 years. Most of them were targeting caudal $\mathrm{Zi}(\mathrm{cZi})$, with different parameters among studies. The therapeutic benefit was prominent, particularly for those tremors difficult to be controlled by VIM, such as proximal postural tremor, distal intension tremor and cerebellar out flow tremor. The complications mostly were mild and transient. There was no lasting or striking dysphasia, dysarthria, or disequilibrium, which could be encountered in VIM DBS, particularly bilateral VIM DBS [26-29]. There was no tolerance either $[9,25]$, another unfavorable feature often reported in VIM DBS [30]. The effect on axial symptoms, such as vocal tremor, head tremor and swallowing function, was rarely mentioned [9]. A good effect on neck tremor was reported on bilateral cZi DBS [9]. DBS on cZi was not found to have negative effect on the swallowing function [33], but have slightly different effect on voice compared to STN DBS [34].

The difference in the specific targets of PSA, the number of DBS placed (unilaterally vs bilaterally), the postsurgical follow -up, and the different diseases studied among these articles makes a concise comparison of clinical benefits and limits of PSA with VIM difficult. A site-to-site comparison among different patients could be more helpful to delineate the difference between the targets. One of the good examples was the study by Hamel et al. [13], who found that cZi DBS at the parameters of $12.7 \mathrm{~mm}$ lateral, $7.0 \mathrm{~mm}$ posterior and 1.5 $\mathrm{mm}$ ventral to the mid-commisural point (MCP) provided better outcome than VIM DBS. Though it is a retrospective study with different post-surgical duration, the site-to-site comparison did provide more reliable comparison of these two targets. A similar result was also reported by another group [11,20,21], with electrodes below the intercommissural line (ICL) producing better outcome in tremor control than those above the ICL [20], though the better outcome meant to be more efficient for cZi than VIM rather than significant difference in individual or maximal stimulation response in these two targets in some studies [20]. More recently, a prospective study designed for direct comparison of $\mathrm{PSA} / \mathrm{cZi}$ with VIM in each individual patient was presented to the $16^{\text {th }}$ MDS meeting in Dublin [35]. The electrode in the study was placed across both PSA/cZi and VIM, which would allow precisely comparing these two targets in the same patient, with both targets targeted in the same side of the brain, or with one target in one side of the brain and the other target in the other side of the brain of the same patient. This design avoids the confounding difference in the disease severity, postsurgical duration, and skills/targets in assessing the DBS efficacy, and allows more accurate site specific assessment (Zi vs VIM). A significantly better outcome in general was found in stimulating cZi than VIM, except that some of the patients could not tolerate the adverse effects of paresthesia in cZi despite the best control of the tremor. The vocal tremor and head tremor were also very well controlled by the stimulation. No worsening of gait was observed after the surgery. The study shows very promising tremor control by cZi DBS, though the conclusion is limited by the small sample size of five patients, as acknowledged by the authors [35]. Stimulating bilateral VIM was also reported to improve vocal tremor and head tremor in some studies as reviewed by Lyons and Pahwa [36], however the occurrence and the worsening of dysarthria and disequilibrium were the concerns in choosing bilateral VIM stimulation in some cases [26-29], and made unilateral VIM DBS as an alternative in certain circumstances [37]. The lack of lasting dysarthria and disequilibrium reported even in bilateral cZI DBS is probably because the cZi DBS only overrides tremor oscillations without interrupting patterns of information related to fine movements of vocal cords and proprioceptive sensation [16].

Besides effective tremor control [11,21,24], cZi was also found to be better than STN in controlling rigidity and bradykinesia without difference in reducing 
dyskinesia and levodopa equivalent dose [11]. The rigidity and bradykinesia was not found to be very well controlled by cZi DBS in another study though [24]. Dystonia was also found to be well controlled by $\mathrm{cZi}$ DBS $[1,16,17]$. More recently, cZi in combination with pedunculopontine nucleus was found to have positive effect on axial symptoms [38]. cZi DBS could also be a target for some patients with ataxia [39].

\section{DBS in PSA: targeting the targets}

As neither cZi nor Raprl can be reliably distinguished on 1.5 Tesla MRI, some used the neighboring structures as reference, such as the STN or VIM, to guide the DBS placement. Most of the studies used posterior and medial to the posterior tail of the STN at the maximal diameter of the red nucleus as the target (Table 1 ). Some of them used the $2-3 \mathrm{~mm}$ under the ventral border of the VIM as the target $[4,35]$. Only a few studies also used microelectrode recording to guide the electrode placement, as cZi gives silent or low activity neuronal background [35], which differentiates cZi from VIM. Imaging targeting in combination with macrostimulation was applied virtually by all studies.

Specifically, the PSA was identified on trans-axial T2weighted MRI images slightly posterior medial to the subthalamic nucleus at the level of the maximal diameter of the red nucleus (Table 1), or about $2-3 \mathrm{~mm}$ below the ventral border of the VIM $[4,35]$. A pre-operative MRI fused with a head CT with stereotactic frame and superimposed digitized Schaltenbrand stereotactic atlas was used to plan the trajectory. The electrode was implanted under local anesthesia. EMR was further used in some studies [35]. The final position of the electrode was dictated by the response to the macrostimulation. A postoperative $\mathrm{x}$-ray was performed before removal of the frame. The location of each electrode contact postsurgically was determined on the postoperative CT infused with the pre-surgical MRI and superimposed atlas. The DBS contact location was determined in relation to the anterior commissure (AC) - posterior commissure (PC) line and the coordinates were plotted onto the Schaltenbrand stereotactic atlas. The efficacy of the stimulation was presented as the result on stimulation in relation to the result off stimulation at the same evaluation, based on clinical exam, UPDRS motor scores, tremor rating scores, daily living function, or quality of life assessment.

\section{DBS in PSA: possible mechanism}

The mechanism of tremor suppression by stimulation in PSA (mostly in cZi) is not entirely clear. The $\mathrm{Zi}$ is a heterogenous nucleus that lies at the base of the dorsal thalamus and is an extension of the reticular /thalamic nucleus [40]. Its rostral component extends over the dorsal and medial surface of the STN, and its caudal or motor component lies posteromedial to the STN $[41,42]$. The ZI receives afferents from the globus pallidus internus (GPi), the substantia nigra reticulate $(\mathrm{SNr})$ $[41,43,44]$, the ascending reticular activating system [43-45], the interpositus nucleus of the cerebellum, and also the motor, associative and limbic areas of the cerebral cortex $[43,46]$. The ZI sends efferents to the centromedian and parafascicular nuclei [47-49], the ventral anterior nucleus and the ventral lateral nucleus of the thalamus [50], the midbrain extrapyramidal area and the medial reticular formation [41], the GPi and $\mathrm{SNr}$ [41], the interpositus nucleus of the cerebellum, the inferior olive and cerebral cortex [51-53]. Current hypotheses regarding the mechanisms of tremor generation point to abnormal synchronisation of neuronal firing in the basal ganglia thalamocortical loop (in PD and DT) or the cerebellar thalamocortical loop (in ET, CT and MS tremor) or both loops (HT) [16]. cZi is an effective target for the surgical control of all forms of tremor because of its unique GABAergic connections with both the basal ganglia and cerebellar thalamocortical loops, in addition to the brain stem motor effectors through which tremor oscillation may be transmitted [16]. Stimulation of the $\mathrm{Zi}$ is likely to suppress the tremor by overriding the oscillations in these areas [16]. Stimulation of the Raprl could similarly abolish contralateral tremor and reduce rigidity [54]. The Raprl is a fiber bundle that lies posterior to the STN, separated from it by the intervening $\mathrm{Zi}$, and consists of fibers from the mesencephalic reticular formation that project to the thalamus as well as ascending cerebellothalamic fibers. How much of the stimulation of the ZI overflows into the neighboring Raprl is unknown and may vary according to individual electrical conductivity of these structures in individual patients. The exact mechanism of how stimulation of PSA suppresses various tremors still awaits further studies to corroborate.

\section{Conclusion}

PSA could potentially be an alternative target for the tremor, particularly for those tremors difficult to be controlled by traditional VIM DBS, including the proximal postural tremor, distal intention tremor, and some cerebellar outflow tremor. The effect of PSA DBS on axial head tremor and vocal tremor also seems to be promising. The adverse effect profile of the PSA appears transient and mild. However, the conclusion is limited by the small numbers of studies so far. More studies, including randomized double-blinded trials comparing the effect of DBS targeting PSA with that targeting VIM, are needed to help us better understand the efficacy and adverse effect profile of the PSA DBS, which could have 
profound effect on tremor control, particularly for those difficult to be controlled by traditional VIM DBS.

\section{Competing interests}

The author(s) declare that they have no competing interests.

\section{Authors' contributions}

TX: Drafting and revising the manuscript; JB: Revising the manuscript; PW: Revising the manuscript. All authors read and approved the final manuscript.

\section{Author details}

'Department of Neurology, University of Chicago Medical Center, Chicago, IL 60637, USA. ${ }^{2}$ Department of Neurosurgery, University of Chicago Medical Center, Chicago, IL 60637, USA.

Received: 2 September 2012 Accepted: 6 October 2012 Published: 29 October 2012

\section{References}

1. Mundinger F: New stereotactic treatment of spasmodic torticollis with a brain stimulation system. Med Klin 1977, 72:1982-1986. German.

2. Brice J, McLellan L: Suppression of intension tremor by contingent deepbrain stimulation. Lancet 1980, 1:1221-1222.

3. Andy OJ: Thalamic stimulation for control of movement disorders. Appl Neurophysiol 1983, 46:107-111.

4. Kitagawa M, Murata J, Kikuchi S, Sawamura Y, Saito H, Sasaki H, Tashiro K: Deep brain stimulation of subthalamic area for severe proximal tremor. Neurology 2000, 55:114-116.

5. Hooper J, Simpson P, Whittle IR: Chronic posttraumatic movement disorder alleviated by insertion of mesodiencephalic deep brain stimulating electrode. Neurosurgery 2005, 56:281-289.

6. Velasco F, Jimenez F, Perez ML, Carrillo-Ruiz JD, Velasco AL, Ceballos J, Velasco M: Electrical stimulation of the prelemniscal radiation in the treatment of Parkinson's disease: an old target revised with new techniques. Neurosurgery 2001, 49:293-306.

7. Murata Jl, Kitagawa M, Uesugi H, Saito H, Iwasaki Y, Kikuchi S, Tashiro K, Sawamura Y: Electrical stimulation of the posterior subthalamic area for the treatment of intractable proximal tremor. J Neurosurg 2003, 99:708-715.

8. Nandi D, Aziz TZ: Deep Brain Stimulation in the Management of Neuropathic Pain and Multiple Sclerosis Tremor. J Clin Neurophysiol 2004, 21:31-39.

9. Plaha P, Patel NK, Gill SS: Stimulation of the subthalamic region for essential tremor. J Neurosurg 2004, 101:48-54

10. Kitagawa M, Murata J, Uesugi H, Kikuchi S, Saito H, Tashiro K, Sawamura Y: Two-year follow-up of chronic stimulation of the posterior subthalamic white matter for tremor-dominant Parkinson's disease. Neurosurgery 2005, 56:281-289.

11. Plaha P, Ben-Shlomo Y, Patel NK, Gill SS: Stimulation of the caudal zona incerta is superior to stimulation of the subthalamic nucleus in improving contralateral parkinsonism. Brain 2006, 129:1732-1747.

12. Freund HJ, Barniko UB, Nolte D, Treuer H, Auburger G, Tass PA, Samii M, Sturm V: Subthalamic-thalamic DBS in a case with spinocerebellar ataxia type 2 and severe tremor-A unusual clinical benefit. Mov Disord 2007, 22:732-735

13. Hemel W, Herzog J, Kopper F, Pinsker M, Weinert D, Muller D, Krack P, Deuschl G, Mehdorn HM: Deep brain stimulation in the subthalamic area is more effective than nucleus ventralis intermedius stimulation for bilateral intention tremor. Acta Neurochir (Wien) 2007, 149:749-758.

14. Herzog J, Hamel W, Wenzelburger R, Potter M, Pinsker MO, Bartussek J, Morsnowski A, Steigerwald F, Deutschl G, Volkmann J: Kinetic analysis of thalamic versus subthalamic neurostimulation in postural and intention tremor. Brain 2007, 130:1608-1625.

15. Carrillo-Ruiz JD, Velasco F, Jimenez F, Castro G, Velasco AL, Hernandez JA, Ceballos J, Velasco M: Bilateral electrical stimulation of prelemniscal radiations in the treatment of advanced Parkinson's disease. Neurosurgeny 2008, 62:347-357.

16. Plaha $\mathrm{P}$, Khan $\mathrm{S}$, Gill SS: Bilateral stimulation of the caudal zona incerta nucleus for tremor control. J Neurol Neurosurg Psychiatry 2008, 79:504-513.

17. Blomstedt P, Fytagoridis A, Tisch S: Deep brain stimulation of the posterior subthalamic area in the treatment of tremor. Acta Neurochir 2009, 151:31-36.
18. Blomstedt $P$, Sandvik U, Tisch S: Deep brain stimulation in the posterior subthalamic area in the treatment of essential tremor. Mov Disord 2010, 25:1350-1356

19. Fytagoridis A, Blomstedt P: Complications and side effects of deep brain stimulation in the posterior subthalamic area. Stereotact Funct Neurosurg 2010, 88:88-93.

20. Barbe MT, Liebhart L, Runge M, Deyng J, Florin E, Wojtecki L, Schnitzler A, Allert N, Sturm V, Fink GR, Maarouf M, Timmermann L: Deep brain stimulation of the ventral intermediate ucleus in patients with essential tremor: stimulation below intercommissural line is more efficient but equally effective as stimulation above. Exp Neurol 2011, 230:131-137.

21. Blomstedt P, Sandvik U, Linder J, Fredricks A, Forsgren L, Hariz MI: Deep brain stimulation of the subthalamic nucleus versus the zona incerta in the treatment of essential tremor. Acta Neurochia (Wien) 2011, 153:2329-2335.

22. Blomstedt $P$, Lindvall $P$, Linder J, Olivecrona M, Forsgren L, Hariz MI: Reoperation after failed deep brain stimualiton for essential tremor. World Neurosurg 2011, Dec [Epub ahead of print].

23. Blomstedt P, Sandvik U, Hariz MI, Fytagoridis A, Forsgren L, Hariz GM, Koskinen LD: Influence of age, gender and severity of tremor on outcome after thalamic and subthalamic DBS for essential tremor. Parkinosnism Relat Disord 2011, 17:617-620.

24. Blomstedt P, Fytagoridis A, Astrom M, Linder J, Forsgren L, Hariz Ml: Unilateral caudal zona incerta deep brain stimulation for Parkinsonian tremor. Parkinsonism Relat Disord 2012, June 13 [Epub ahead of print].

25. Fytagoridis A, Sandvik U, Astrom M, Bergenheim T, Blomstedt P: Long term follow-up of deep brain stimulation of the caudal zona incerta for essential tremor. J Neurol Neurosurg Psychiatry 2012, 83:258-262.

26. Pahwa R, Lyons KE, Wilkinson SB, Simpson RK Jr, Ondo WG, Tarsy D, Norregaard T, Hubble JP, Smith PA, Hauser RA, Jankovic J: Long-term evaluation of deep brain stimulation of the thalamus. J Neurosurg 2006, 104:506-512.

27. Hariz GM, Lindberg M, Bergenheim AT: Impact of thalamic deep brain stimulation on disability and health-related quality of life in patients with essential tremor. J Neurol Neurosurg Psychiatry 2002, 72:47-52.

28. Blomstedt P, Hariz Ml: Are complications less common in deep brain stimulation than in ablative procedures for movement disorders? Stereotact Funct Neurosurg 2006, 84:72-81.

29. Blomstedt P. Hariz GM, Hariz MI, Koskinen LO: Thalamic deep brain stimulation in the treatment of essential tremor: a long-term follow-up. Br J Neurosurg 2007, 21:504-509.

30. Hariz Ml, Shamsgovara P, Johansson F, Hariz G, Fodstad H: Tolerance and tremor rebound following lomg-term chronic thalamic stimulation for Parkinsonian and essential tremor. Stereotact Funct Neurosurg 1999 72:208-218

31. Atlasa Schaltenbrand G, Wahren W: Atlas for Stereotaxy of the Human Brain Stuttgart: Thieme; 1977

32. Benabid AL, Pollak P, Louveau A, Henry S, de Rougemont J: Combined (thalamotomy and stimulation) stereotactic surgery of the VIM thalamic nucleus for bilateral Parkinson disease. App/ Neurophysiol 1987, 50:344-346.

33. Sundstedt S, Olofsson K, van Doorn J, Linder J, Nordh Em Blomstedt P: Swallowing function in Parkinson's patients following Zona Incerta deep brain stimulation. Acta Neurol Scand 2012, Mar 4 [Epub ahead of print].

34. Lundgren S, Saeys T, Karlsson F, Olofsson K, Blomstedt P, Linder J, Nordh E, Zafar $\mathrm{H}$, van Doorn J: Deep brain stimulation of caudal zona incerta and subthalamic nucleus in patients with Parkinson's disease: effects on voice intensity. Parkinsons Dis 2011, Oct 19 [Epub].

35. Xie T, Bernard J, Ojakangas C, Kang UJ, Towle VL, Wranke P: Deep brain stimulation in the caudal zona incerta and posterior subthalamic area is more effective than in ventral intermediate nucleus for various tremor control. In $16^{\text {th }}$ International Congress of Parkinson's Disease and Movement Disorders, Dublin, Ireland; 2012:979.

36. Lyons KE, Pahwa R: Deep brain stimulation and essential tremor. J Clin Neurophysiol 2004, 21:2-5.

37. Xie T, Goodman R, Browner N, Haberfeld E, Winfield L, Goldman J, Ford B: Treatment of fragile $X$-associated tremor/ataxia syndrome with unilateral deep brain stimulation. Mov Disord 2012, 27:799-800.

38. Khan S, Mooney L, Plaha P, Javed S, White P, Whone AL, Gill SS: Outcomes from stimulation of the caudal zona incerta and pedunculopontine nucleus in patients with Parkinson's disease. Br J Neurosurg 2011, 25:273-280

39. Oyama G, Thompson AJ, Limotai N, Maling N, Abd-El-Barr M, Foote K, Subramony SH, Ashizawa T, Okun M: Tailing DBS treatment for tremor and 
dystonia associated with various ataxia syndromes: a case series. In $16^{\text {th }}$ International Congress of Parkinson's Disease and Movement Disorders, Dublin, Ireland; 2012:606.

40. Yen $\mathrm{CT}$, Conley M, Hendry SH, Jones EG: The morphology of physiologically identified GABAergic neurons in the somatic sensory part of the thalamic reticular nucleus in the cat. J Neurosci 1985, 5:2254-2268.

41. Heise CE, Mitrofanis J: Evidence for a glutamatergic projection from the zona incerta to the basal ganglia of rats. J Comp Neurol 2004, 468:482-495.

42. Mitrofanis J: Some certainty for the "zone of uncertainty"? Exploring the function of the zona incerta. Neuroscience 2005, 130:1-15.

43. Roger M, Cadusseau J: Afferents to the zona incerta in the rat: a combined retrograde and anterograde study. J Comp Neurol 1985, 241:480-492.

44. Shammah-Lagnado SJ, Negrao N, Ricardo JA: Afferent connections of the zona incerta: a horseradish peroxidase study in the rat. Neuroscience 1985, 15:109-134.

45. Watanabe K, Kawana E: The cells of origin of the incertofugal projections to the tectum, thalamus, tegmentum and spinal cord in the rat: a study using the autoradiographic and horseradish peroxidase methods. Neuroscience 1982, 7:2389-2406.

46. Mitrofanis J, Mikuletic $L$ : Organisation of the cortical projection to the zona incerta of the thalamus. J Comp Neurol 1999, 412:173-185.

47. Power $\mathrm{BD}$, Mitrofanis J: Ultrastructure of afferents from the zona incerta to the posterior and parafascicular thalamic nuclei of rats. J Comp Neurol 2002, 451:33-44

48. Power BD, Mitrofanis J: Specificity of projection among cells of the zona incerta. J Neurocytol 1999, 28:481-493.

49. Power BD, Mitrofanis J: Evidence for extensive inter-connections within the zona incerta in rats. Neurosci Lett 1999, 267:9-12.

50. Bartho P, Freund TF, Acsady L: Selective GABAergic innervation of thalamic nuclei from zona incerta. Eur J Neurosci 2002, 16:999-1014.

51. Lin CS, Nicolelis MA, Schneider JS, Chapin JK: A major direct GABAergic pathway from zona incerta to neocortex. Science 1990, 248:1553-1556.

52. Lin CS, Nicolelis MA, Schneider JS, Chapin JK: GABAergic pathway from zona incerta to neocortex: clarification. Science 1991, 251:1162

53. Nicolelis MA, Chapin JK, Lin RC: Development of direct GABAergic projections from the zona incerta to the somatosensory cortex of the rat. Neuroscience 1995, 65:609-631.

54. Jiménez F, Velasco F, Velasco M, Brito F, Morel C, Márquez I, Pérez ML: Subthalamic prelemniscal radiation stimulation for the treatment of Parkinson's disease: Electrophysiological characterization of the area. Arch Med Res 2000, 31:270-281.

doi:10.1186/2047-9158-1-20

Cite this article as: Xie et al:: Post subthalamic area deep brain stimulation for tremors: a mini-review. Translational Neurodegeneration 2012 1:20

\section{Submit your next manuscript to BioMed Central and take full advantage of:}

- Convenient online submission

- Thorough peer review

- No space constraints or color figure charges

- Immediate publication on acceptance

- Inclusion in PubMed, CAS, Scopus and Google Scholar

- Research which is freely available for redistribution 